Were the volume to have explicitly embedded civil society into a sociologicallyoriented theory of democracy, like Charles Tilly's now old notion of equal, broad, protected, and mutually-binding consultations between society and state (Democracy, Cambridge, 2007), then we would have a clear normative frame that could find new knots to pick at, like who in the community deserves consultation and how markets can undermine democracy's norms. If we had the kind of empirical richness and theoretical awareness of this volume to inform those asocial democratic accounts focusing only on governmental forms, we might have the start of a theory not only accounting for authoritarianism's return, but maybe even an appropriately-emancipatory theory of civil society to mobilize.

MiCHAEL D. KENNEDY Brown University

Fragile Conviction: Changing Ideological Landscapes in Urban Kyrgyzstan. By Mathijs Pelkmans. Ithaca: Cornell University Press, 2017. xii, 213 pp. Notes. Bibliography. Index. Illustrations. Photographs. \$89.95, hard bound, \$26.95, e-book. doi: 10.1017/slr.2018.246

Conviction connects subjects to ideology. This is obvious. But how does it do that? This is a more interesting question, and it is the topic of Mathijs Pelkmans's insightful new ethnography, Fragile Conviction: Changing Ideological Landscapes in Urban Kyrgyzstan (2017). Pelkmans has been visiting Kyrgyzstan for over twenty years. He draws on this history to offer insights that are both intellectually sophisticated and temporally informed. The ethnographic material here is loosely focused on Kokjangak, a struggling former mining town in southern Kyrgyzstan. This is not a village ethnography, however. Pelkmans's unifying theme is conceptual. Like many ethnographers who work in the region, he is preoccupied by how people face insecurity and instability; he is interested in how people find (or don't find) hope in the form of belief.

Before independence in 1991, the Soviet state was a source of hope, not least of all because it offered economic stability. The current neoliberal state, in contrast, offers only anxiety. Pelkmans acknowledges the conventional wisdom that "conviction thrives in contexts of instability" (170), but he recognizes this leaves a lot unexplored. Why does conviction come on strong only to dissipate? How does conviction persist if it is so fragile? The key to understanding these "volatile dynamics" (70), according to Pelkmans, is pulsation. Pulsation has three moments. The first moment is an impulse, a flash of energy. The second moment is the expansion of that impulse as it gains "traction" (176). The third moment is contraction. This is not a contraction into nothing, but a retreat in preparation for the next expansion.

Pelkmans offers several case studies to illustrate the dynamics of pulsation. In a chapter on Soviet atheism, he argues the ideology failed because it did not make the type of utopian promises that instigate these volatile dynamics of pulsation. In contrast, Tablighi Jamaat, an international Islamic piety movement with followers in Kyrgyzstan, has seemingly mastered the dynamics of pulsation. It requires its adherents to commit to periodic dawats (proselytizing trips), during which adherents leave jobs and families behind to spend time with other adherents and energize their faith. Pelkmans joins a dawat one weekend, traveling with the group of seven men to a nearby village where they take up residence in its mosque, periodically venturing out to the community to invite people to the mosque to learn about Islam. He is struck by 
the men's passion. In later interviews, however, he discovers that not all the men can maintain their conviction between dawats; some men attend the next dawat reluctantly, others disappear completely, their conviction too fragile to overcome the third phase of the pulsation.

A case study on Pentecostal congregations in southern Kyrgyzstan adds subtlety to this account of conviction's fragility. The Kyrgyz pastor building the congregations attracts interest in part with his miraculous healings. Pelkmans listens to converts talk about the miracles, noting the initial burst of hope that dissipates into ambivalence or even doubt until energized by a new miracle (a parallel chapter on spiritualist healers documents similar dynamics). In addition to miracles, the pastor attracts followers with the familiar Christian prosperity gospel, according to which the faithful will be rewarded with health and wealth. In Jalalabad, a prosperous town, this gospel works well. Many congregants find professional and financial success in the city. They use their success to help others in the church, and this allows the church to grow in number and strength. The prejudice church members face in the larger community only intensifies their commitment to the church and its teachings. In Kokjangak, the struggling former mining town, the congregation is too small to find strength in external hostility, and there is not enough opportunity in the town to make the prosperity gospel resonate. The congregation fails to grow. The pastor, frustrated, blames this failure on weak faith. Pelkmans concludes instead that belief thrives where there is the correct balance between desperation and opportunity, and Kokjangak could not offer that balance.

At moments in the book, I felt overwhelmed by the number and complexity of metaphors Pelkmans introduces, even if I could acknowledge that each metaphor added subtlety to the discussion of belief. Pelkmans's insights are an important corrective to simplistic views of religion and economic chaos. He concludes that in unstable Kyrgyzstan, no idea is completely routinized. Motivational ideas direct the seeker's attention to a utopian horizon. The success of each idea lies in its ability to energize faith in that horizon, even if that horizon can never be reached.

\author{
NOOR O’NEILl BoRbievA \\ Indiana University \\ Purdue University, Fort Wayne
}

\title{
Azan on the Moon: Entangling Modernity along Tajikistan's Pamir Highway. By Till Mostowlansky. Pittsburgh: University of Pittsburgh Press, 2017. xx, 216 pp. Notes. Bibliography. Index. Photographs. Maps. \$26.95, paper. doi: 10.1017/slr.2018.247
}

Readers rarely associate anthropology with highways. However, this is the setting of Till Mostowlansky's research in Gorno (Mountainous) Badakhshan, Tajikistan's easternmost region, abutting Afghanistan, China, and Kyrgyzstan. Billed as a study of modernity, the author's explanation reveals his interest in what Soviet transformation meant to Tajikistanis. What did it mean regarding remnants of the national, the traditional, and the uniquely local that anthropologists use to understand how larger entities imposed their will and changed culture in this nook of the Soviet world since the 1930s?

Mostowlansky asserts that allowing people to represent themselves illuminates ideas of modernity and traditionalism. Furthermore, self-representations give us a more grounded understanding of linguistic and ethnic complexity than one gains from outsiders' perspectives (even as it takes an outsider to bring it to light). 